University of Nebraska - Lincoln

DigitalCommons@University of Nebraska - Lincoln

Faculty Papers and Publications in Animal

Science

Animal Science Department

September 2002

\title{
Maternal behavior in mice selected for large litter size
}

\author{
Chung-Feng Chiang \\ University of Nebraska-Lincoln \\ Rodger . K. Johnson \\ University of Nebraska-Lincoln, rjohnson5@unl.edu \\ Merlyn K. Nielsen \\ University of Nebraska-Lincoln, mnielsen1@unl.edu
}

Follow this and additional works at: https://digitalcommons.unl.edu/animalscifacpub

Part of the Animal Sciences Commons

Chiang, Chung-Feng; Johnson, Rodger . K.; and Nielsen, Merlyn K., "Maternal behavior in mice selected for large litter size" (2002). Faculty Papers and Publications in Animal Science. 114.

https://digitalcommons.unl.edu/animalscifacpub/114

This Article is brought to you for free and open access by the Animal Science Department at DigitalCommons@University of Nebraska - Lincoln. It has been accepted for inclusion in Faculty Papers and Publications in Animal Science by an authorized administrator of DigitalCommons@University of Nebraska - Lincoln. 
Published in Applied Animal Behaviour Science 79:1 (September 20, 2002), pp. 63-73.

Copyright (C) 2002 Elsevier Science B.V. Used by permission.

Accepted June 5, 2002.

Paper number 13507, Journal Series, Nebraska Agriculture Research Division, University of Nebraska-Lincoln.

\title{
Maternal behavior in mice selected for large litter size
}

\author{
Chung-Feng Chiang, Rodger K. Johnson, * and Merlyn K. Nielsen \\ Department of Animal Science, University of Nebraska-Lincoln, Lincoln, NE 68583-0908 USA \\ * Corresponding author: tel 402 472-6404; fax 402 472-6362; email rijohnson5@unl.edu
}

\begin{abstract}
A total of 96 lactating mice and their pups from each of three replications of lines selected 21 generations for increased litter size (LS) followed by 23-25 generations of random selection and contemporary unselected control lines (LC) were characterized for maternal behavior. Sixteen dams and their pups from each replication of LS and LC lines were sampled. Litter sizes at birth for LS versus LC in the first, second, and third replicates were 17.3 versus $13.2,15.9$ versus 13.1 , and 12.3 versus 10.6 pups, respectively, with LS dams averaging $2.87 \pm .70$ pups more. One-half of the litters were standardized to either 12 pups (Replications 1 and 2) or 8 pups (Replication 3) on day 1 of lactation; the others were not standardized. Behavioral categories included time dams spent: (1) nursing pups, (2) licking pups, (3) retrieving pups, (4) nest building, (5) resting with pups. (6) resting alone, (7) eating and drinking, (8) grooming, and (9) in other activities. Categories one through five were summed as an index of maternal behavior. Activities during 30 min observation periods from days 2 to 22 of lactation were recorded. Interactions of line by stage of lactation (days 2-4, 5-8, 9-12, 13-17, and 18-22) and line by litter standardization were not significant for any trail except time spent resting with pups (line $\times$ stage, $P=0.03$ ).

The maternal behavior index was $7.0 \pm 2.2 \%$ greater $(P=0.08)$ for LS than LC dams. The difference was due mostly to increased time LS dams spent nursing pups (LS - LC = $9.7 \pm 2.1 \%, P=0.04)$. Averaged across lactation stages, LS dams tended to spend less time resting with their pups $(-2.32 \pm 1.04 \%, P=0.15)$ than LC dams, but the difference was greatest and significant only in the last stage $(-10.45 \pm 2.20, P<0.01)$. Selection for larger litters altered maternal behavior by increasing the time dams spent nursing pups. Interaction of line by litter size standardization existed for pup survival to weaning $(P=0.03)$. Survival of pups in standardized litters raised by LS dams was $10.4 \pm 4.9 \%$ greater $(P=$ $0.04)$ than in standardized LC litters whereas line difference in non-standardized litters was not significant $(P>0.30)$. Because interactions of line by litter size standardization for maternal behavior traits were not significant, correlated responses in maternal behavior were considered to be independent of size of litter being nursed.
\end{abstract}

Keywords: mice, litter size, selection, maternal behavior, pre-weaning growth, pre-weaning survival 


\section{Introduction}

Pre-weaning mortality of piglets is a major loss to the pig industry and is often due to crushing by sows (Cronin, 1985; Spicer et al., 1986; Vaillancourt and Tubbs, 1992; Maderbacher et al., 1993; White et al., 1996). Farrowing crates were introduced in the 1960 s to reduce the rate of piglet crushing. Today, this management practice is commonplace.

Maternal behavior is thought to be important to pre-weaning survival and growth of offspring because few species of mammals have young that can survive in the absence of maternal care without special diets and environments. Modification of the parturient and lactation environment of the sow could improve maternal behavior. Some researchers have found that improvement of maternal behavior in sows through environmental modification will improve pre-weaning growth of litters (Cronin and Smith, 1992; Lou and Hurnik, 1994; Arey and Sancha, 1996) and survival of piglets (Cronin and van Amerongen, 1991; Cronin and Smith, 1992). However, other researchers have reported that attempts to improve maternal behavior did not promote piglet pre-weaning survival and growth (Cronin et al., 1994; Cronin et al., 1996).

There may be an alternative way to improve maternal performance. Prolific Chinese-breed sows, such as Meishan, spend more time nursing their litters than Chinese-Western crossbred sows (Schouten and Meunier-Salaun, 1990). In a cross-fostering trial, van der Steen and de Groot (1992) found that piglets reared by Meishan sows had higher pre-weaning survival and growth rates than those reared by Dutch Landrace sows. Meishan sows have also been reported to produce higher quality milk than European breeds (Zou et al., 1992). These breed differences suggest that genetic differences in maternal behavior may be related to piglet growth and survival.

The main objective of this study was to determine whether genetic differences in maternal behavior exist between lines of mice selected for litter size. Litter weight gains to weaning and pre-weaning mortality were also compared to relate line differences in these traits to maternal behavior.

\section{Material and methods}

\subsection{Animals}

Maternal behavior was characterized in a total of 96 primiparous, lactating females with their pups. They were samples of 16 dams and litters from each of three replicates of lines previously selected 21 generations for increased litter size (LS) and contemporary randomly selected control lines (LC). All six replicate/selection lines originated from the same base population (Clutter et al., 1990; Kirby and Nielsen, 1993). Replicates were separated in time by approximately 5 weeks. 
Table 1. Mean number of live pups per litter for experimental dams, all dams of the current generation, and all dams of the preceding generation

\begin{tabular}{|c|c|c|c|c|c|c|c|}
\hline \multirow[t]{2}{*}{ Generation } & \multirow[t]{2}{*}{ Line } & \multicolumn{2}{|c|}{$\begin{array}{l}\text { Experimental } \\
\text { dams }\end{array}$} & \multicolumn{2}{|c|}{$\begin{array}{l}\text { All dams of } \\
\text { current generation }\end{array}$} & \multicolumn{2}{|c|}{$\begin{array}{l}\text { All dams of the } \\
\text { preceding generation }\end{array}$} \\
\hline & & $n$ & Mean & $n$ & Mean & $n$ & Mean \pm S.E.M. \\
\hline \multicolumn{8}{|l|}{ Replication 1} \\
\hline \multirow{2}{*}{46} & $\mathrm{LC}$ & 16 & $13.2 \pm 0.44$ & 51 & $12.4 \pm 0.40$ & 38 & $11.9 \pm 0.50$ \\
\hline & LS & 16 & $17.3 \pm 0.68$ & 48 & $16.5 \pm 0.47$ & 39 & $15.6 \pm 0.73$ \\
\hline \multicolumn{8}{|l|}{ Replication 2} \\
\hline \multirow[t]{2}{*}{45} & $\mathrm{LC}$ & 16 & $13.1 \pm 0.46$ & 53 & $11.7 \pm 0.42$ & 39 & $10.7 \pm 0.40$ \\
\hline & LS & 16 & $15.9 \pm 0.51$ & 55 & $15.5 \pm 0.40$ & 40 & $14.1 \pm 0.52$ \\
\hline \multicolumn{8}{|l|}{ Replication 3} \\
\hline \multirow[t]{2}{*}{44} & $\mathrm{LC}$ & 16 & $10.6 \pm 0.73$ & 53 & $10.2 \pm 0.35$ & 39 & $9.7 \pm 0.42$ \\
\hline & LS & 16 & $12.3 \pm 0.50$ & 52 & $12.9 \pm 0.35$ & 39 & $13.2 \pm 0.46$ \\
\hline
\end{tabular}

Following termination of selection, both LS and LC lines in each replicate were maintained with approximately 40 litters per generation and with random selection of one male and two female breeders from 20 of the 40 litters. The dams evaluated in the current experiment were from Generations 46 (Replication 1), 45 (Replication 2), and 44 (Replication 3). Replicates were evaluated in the order of Replication 3, Replication 2, and Replication 1, which is the explanation for the different number generations of relaxed selection. Mean litter sizes of the LS and LC dams evaluated were 17.3 versus 13.2, 15.9 versus 13.1, and 12.3 versus 10.6, in Replications 1,2, and 3, respectively. These means are similar to means for all females in the generation from which the mice were sampled as well as the mean litter sizes of the preceding generation (Table 1).

In Replicates 1 and 2, eight of the 16 experimental dams per line were randomly chosen to have their litters standardized to 12 pups, and in Replicate 3 litters of eight experimental dams per line were standardized to 8 pups. Pups were removed from dams with more than target numbers of pups and transferred to dams of the same line with fewer than target numbers. Most experimental dams in LS lines had more than target numbers of pups and in these litters, excess pups were euthanized. Pups were chosen randomly for transfer. Transfer of pups occurred only within line and was done on the day litters were born. The other eight experimental dams per line in each replicate raised their natural litter. Standardized litter size in each replication was based on the average litter size of the first 20 of the LC litters in each replication.

\subsection{Environment and management}

The laboratory was kept at $24{ }^{\circ} \mathrm{C}$ with $12 \mathrm{~h}$ light: $12 \mathrm{~h}$ dark cycles. Mice in littering cages had ad libitum access to water and a rodent-block diet containing 


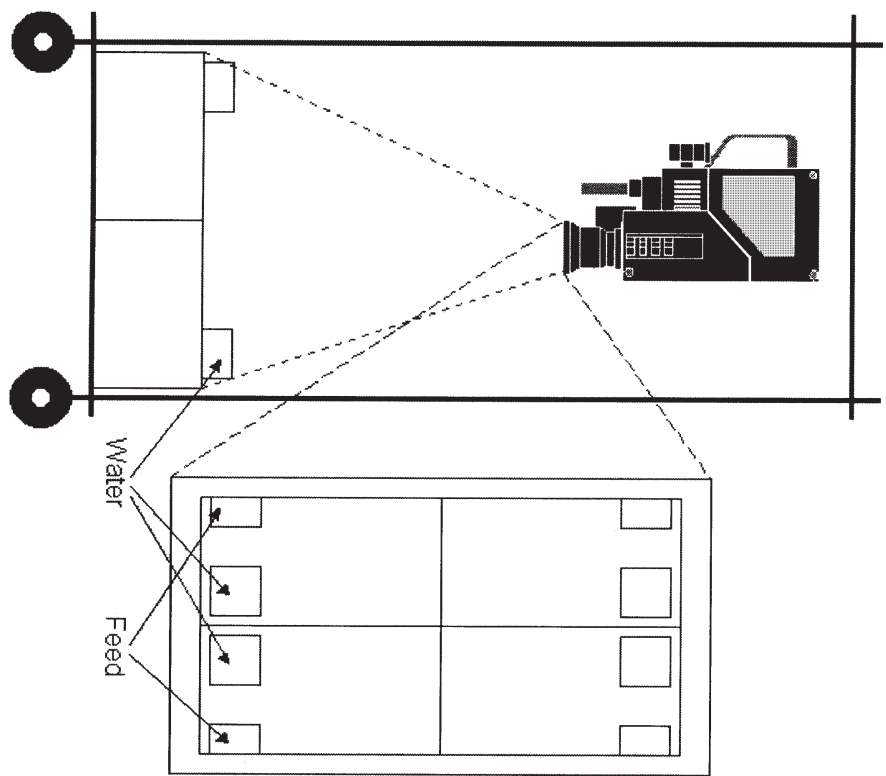

Figure 1. Set-up of mouse cages and video camera. Behavior of four dams with their litters was recorded simultaneously. Water and feed were provided at outer location to avoid observation obstacles. Focus of the video camera was adjusted to ensure complete view of all four cages.

$20 \% \mathrm{CP}, 10 \%$ fat, and $2 \%$ crude fiber. Cages were $15.24 \mathrm{~cm} \times 30.48 \mathrm{~cm} \times 15.24$ $\mathrm{cm}$ covered with metal mesh lids with $1.27 \mathrm{~cm}^{2}$ openings in the mesh. In growing and breeding cages, mice had ad libitum access to water and to a rodent-block diet containing $24 \% \mathrm{CP}, 4 \%$ fat, and $4.5 \%$ fiber. Two to three females in a cage were mated to a non-sibling male at the age of 12 weeks, females were observed for vaginal plugs, and pregnant mice were transferred individually to their own littering cage at the 18th day of gestation. Cages were checked daily for new litters. The day when the litter was found was assumed to be the day of birth.

\subsection{Behavioral data}

Real-time video cameras were used to record behavioral activities of dams and litters. Recording occurred daily during three time periods from 09.00 to 12.00 , 12.00 to 15.00 , and 15.00 to $18.00 \mathrm{~h}$ from days 2 to 22 of lactation, with date of birth counted as day 0 . All 32 dams and their litters (16 per line) within each replication were recorded during each time period. Two cameras were used. Four cages containing two LS and two LC dams and their litters were positioned randomly under each camera as illustrated in Figure 1. The order in which mice were viewed during each time period was also random. During each time period, each group of four dams and litters was recorded for $30 \mathrm{~min}$.

After recording of mice within each replication was competed, tapes were viewed and behavior was scored. At $30 \mathrm{sec}$ intervals as the videotape was viewed, the recorder scored behavioral activities of all four dams shown in the view us- 
ing the following behavioral categories (Krackow and Hoeck, 1989): (1) nursing: the dam was in the lactation position described by Salor and Salmon (1971) or at least one pup was visibly suckling, (2) licking pups: the dam was licking any part of a pup's body, (3) retrieving pups: the dam carrying or attempting to carry a pup in the direction of the nest by taking a part of the pup's body into her mouth, (4) nest building: the dam transporting material toward the nest or manipulating already incorporated material, (5) resting with pups: the dam was inactive and not engaged in any denned behavior, but a part of her body, other than the tail, was in contact with the body of at least one pup, (6) resting alone: the dam was inactive and not in contact with any pup, (7) eating and drinking: the dam ingesting food or water, (8) grooming: the dam wiping, licking, or scratching her body, and (9) other: activities such as running, sniffing and climbing on bars not assigned to another category. Each dam had 60 behavior scores during each time period and 180 scores per day. The frequency of each score within each time period was divided by 60 and then multiplied by 100 to express it as a percentage. These percentages were averaged to express the percentage of time during the $9 \mathrm{~h}$ period from 09.00 to $18.00 \mathrm{~h}$ that mice were observed in each category. Categories one through five were considered to be maternal care, and percentages for these activities were summed to give a maternal behavior index.

\subsection{Performance data}

Number born alive (NBA) was recorded in mice of each replicate. Number weaned (NW), litter weight at birth, and litter weight at weaning were recorded only in Replicates 1 and 2.

\subsection{Data analysis}

For analysis of behavior data, days $2-22$ of lactation were divided into five stages: days $2-4,5-8,9-12,13-17$, and $18-22$. The model fitted to the data was:

$$
\begin{gathered}
Y_{i j k l m}=\mu+r_{i}+l_{j}+d_{k}+(r l)_{i j}+(r d)_{i k}+(l d)_{j k}+(r l d)_{i j k}+a(r l d)_{i j k m}+s_{l}+(l s)_{i l} \\
+(r s)_{i k}+(d s)_{k l}+(r l s)_{i j l}+(r d s)_{i k l}+(l d s)_{j k l}+(r l d s)_{i j k l}+e_{i j k l m}
\end{gathered}
$$

where $Y_{i j k l m}$ is the $m$ th observation from the $i$ th replicate, the $j t h$ line, and the $k$ th standardization group at the $l$ th stage, $\mu$ the overall mean, $r_{i}$ the random effect of the $i$ th replication, $l_{j}$ the fixed effect of the $j$ th selection line, $d_{k}$ the fixed effect of the $k$ th standardization, $(r l)_{i j}$ the random effect of replication by line interaction, $(r d)_{i k}$ the random effect of replication by standardization interaction, $(l d)_{j k}$ the fixed effect of line by standardization interaction, $(r l d)_{i j k}$ the random effect of the replication by line by standardization interaction, $a(r l d)_{i j k m}$ the random effect of the $m$ th animal within line, replication, and standardization, $s_{l}$ the fixed effect of the $l$ th stage of lactation, $(l s)_{i l}$ the fixed effect of line by stage interaction, $(r s)_{i k}$ the random effect of replication by stage interaction, $(d s)_{k l}$ the fixed effect of standardization by stage interaction, $(r l s)_{i j l}$ the random effect of replication by line by stage interaction, $(r d s)_{i k l}$ the random effect of replication by standardization by stage interaction, $(l d s)_{j k l}$ the fixed effect of line by standardization by stage 
interaction, $(r l d s)_{i j k l}$ the random effect of replication by line by standardization by stage interaction, and $e_{i j k l m}$ the random error associated with that observation.

Analyses were done with SAS Proc Mixed (Little et al., 1996). For performance data, because there was no stage effect, the model included effects of replication, line, standardization and their interactions. In all models, effects were tested with appropriate error variances as determined by the Satterthwaite procedure in SAS.

\section{Results}

Table 2 contains degrees of freedom and probabilities associated with tests of fixed effects in models of litter traits. Means are in Table 3. The experimental LS dams had $2.87 \pm 0.70$ more live pups per litter $(P=0.06)$ than LC dams, although the difference in total litter birth weight was not significant. Averaged across litters standardized to 12 pups and natural litter sizes in Replications 1 and 2, LS dams had larger litters at weaning than LC dams $(1.63 \pm 0.51$ pups, $P<0.01)$ and their litters gained more weight from birth to weaning $(11.7 \pm 5.1 \mathrm{~g}, P==0.03)$, and thus, were heavier at weaning $(12.8 \pm 5.2 \mathrm{~g}, P=0.02)$. Natural litters were larger at weaning ( $0.91 \pm 0.51$ pups, $P=0.08)$, but survival rate, weight gain of pups, and litter weaning weight were greater in standardized litters $(10.9 \pm 3.3 \%, P<0.01 ; 12.3 \pm 5.1 \mathrm{~g}$, $P=0.02$; and $9.2 \pm 5.2 \mathrm{~g}, P=0.08$; respectively). Interaction of line by litter size standardization existed only for survival of pups $(P=0.03)$. Survival of pups was $10.4 \pm 4.9 \%$ greater in standardized LS litters than LC litters, whereas survival in natural litters was $-4.6 \pm 4.6 \%$ less in LS than in LC litters. As a result, weight gain in standardized litters was $17.4 \pm 7.5 \mathrm{~g}$ greater in LS than in LC litters, whereas in natural litters weight gain of LS litters was $6.1 \pm 7.0$ g greater.

Table 4 contains degrees of freedom and probabilities associated with tests of fixed effects in models of behavior traits. Means for traits for which line effects or interactions with lines were significant are in Table 5. Interactions among fixed effects existed only for the percentage of time dams were observed resting with pups (line by stage of lactation, $P=0.03$ ), percentage of time spent retrieving pups (litter size standardization by stage of lactation, $P<0.08$ ) and the maternal

Table 2. Numerator (num), and denominator (Den), degrees of freedom (d.f.) ${ }^{\mathrm{a}}$, and probability of a greater $F$-ratio $(P>F)$ for effects in models of production traits ${ }^{\mathrm{b}}$ recorded at birth and weaning

\begin{tabular}{|c|c|c|c|c|c|c|c|c|c|c|c|c|c|}
\hline \multirow[t]{2}{*}{ Effect $^{c}$} & \multirow{2}{*}{$\begin{array}{l}\text { Num } \\
\text { d.f. }\end{array}$} & \multicolumn{2}{|l|}{ LSB } & \multicolumn{2}{|l|}{ LBW } & \multicolumn{2}{|l|}{ LSW } & \multicolumn{2}{|l|}{ LWW } & \multicolumn{2}{|l|}{ Survival } & \multicolumn{2}{|l|}{ WG } \\
\hline & & Den d.f. & $P>F$ & Den d.f. & $P>F$ & Den d.f. & $P>F$ & Den d.f. & $P>F$ & Den d.f. & $P>F$ & Den d.f. & $P>F$ \\
\hline Line & 1 & 1.99 & 0.06 & 2.25 & 0.36 & 54.9 & $<0.01$ & 55 & 0.02 & 54.4 & 0.39 & 54 & 0.03 \\
\hline LTRT & 1 & & & & & 54.3 & 0.08 & 55 & 0.08 & 54.1 & $<0.01$ & 54 & 0.02 \\
\hline $\begin{array}{r}\text { Line } \times \\
\text { LTRT }\end{array}$ & 1 & & & & & 54.7 & 0.57 & 55 & 0.64 & 54.3 & 0.03 & 54 & 0.28 \\
\hline
\end{tabular}

${ }^{a}$ Due to use of the Satterthwaite procedure, degrees of freedom are not always whole numbers. See description of data analysis procedures in Section 2.

b LSB: number born per litter, LBW: litter birth weight, LSW: number weaned per litter, LWW: litter weaning weight, Surv: percentage of pups after transfer that survived to weaning, WG: weight gain of pups after transfer from birth to weaning.

${ }^{\mathrm{c}}$ LTRT: effect of natural vs. standardized litter size. 
Table 3. Means for production traits ${ }^{\mathrm{a}}$ and contrasts among means \pm S.E. for litter size control and select lines without $(\mathrm{N})$ and with $(\mathrm{Y})$ standardized litter sizes at birth

\begin{tabular}{|c|c|c|c|c|c|c|}
\hline Item $^{b}$ & LSB & LBW (g) & LSW & LWW(g) & Surv (\%) & WG (g) \\
\hline \multicolumn{7}{|l|}{ Means } \\
\hline $\mathrm{LCN}$ & $12.3 \pm 1.24$ & $20.0 \pm 0.68$ & $11.27 \pm 0.51$ & $114.4 \pm 5.2$ & $85.6 \pm 4.2$ & $94.2 \pm 5.0$ \\
\hline LCY & & & $10.65 \pm 0.53$ & $121.1 \pm 5.4$ & $89.0 \pm 4.3$ & $100.8 \pm 5.4$ \\
\hline LSN & $15.17 \pm 1.24$ & $21.1 \pm 0.63$ & $13.19 \pm 0.49$ & $124.8 \pm 5.0$ & $81.0 \pm 4.1$ & $100.3 \pm 4.9$ \\
\hline LSY & & & $11.99 \pm 0.53$ & $136.4 \pm 5.4$ & $99.4 \pm 4.3$ & $118.2 \pm 5.2$ \\
\hline \multicolumn{7}{|l|}{ Contrasts } \\
\hline LS - LC & $2.87 \pm 0.70^{+}$ & $1.1 \pm 0.93$ & $1.63 \pm 0.51^{+}$ & $12.8 \pm 5.2^{*}$ & $2.9 \pm 3.3$ & $11.7 \pm 5.1^{*}$ \\
\hline $\mathrm{Y}-\mathrm{N}$ & & & $-0.91 \pm 0.51^{+}$ & $9.2 \pm 5.2^{+}$ & $10.9 \pm 3.3 * *$ & $12.3 \pm 5.1 *$ \\
\hline $\mathrm{LSN}-\mathrm{L}$ & & & $1.92 \pm 0.70^{* *}$ & $10.4 \pm 7.2$ & $-4.6 \pm 4.6$ & $6.1 \pm 7.0$ \\
\hline LSY - LC & & & $1.35 \pm 0.74^{+}$ & $15.3 \pm 7.6^{*}$ & $10.4 \pm 4.9^{*}$ & $17.4 \pm 7.5^{*}$ \\
\hline
\end{tabular}

a LSB: number born per litter, BW: litter birth weight, LSW: number weaned per litter, LWW: litter weaning weight, Surv: percentage of pups after transfer that survived to weaning, WG: weight gain of pups after transfer from birth to weaning.

${ }^{\mathrm{b}}$ LCN, LCY: litter size control line without and with litter size standardization, LSN and LSY: litter size select line with and without litter size standardization, LS - LC: contrast of LS - LC, etc.

${ }^{+} P<0.10 . \quad * P<0.05 . \quad * * P<0.01$.

behavior index (litter size standardization by stage of lactation, $P=0.07$ ). Lines differed only for the percentage of time they spent nursing pups $(P=0.04)$, and the maternal behavior index $(P=0.08)$.

On average LS dams were observed nursing pups $64.7 \%$ of the time compared with $55.0 \%$ for LC dams. The time dams nursed pups declined with stage of lactation averaging $72.2 \%$ during stage 1 and $43.3 \%$ during stage 5 . LS dams spent more time nursing pups than LC dams during all stages, but differences were greatest in stages 1 and 2 and again in stage 5 when there was a sharp reduction in nursing time by LC dams. Responses in the maternal behavior index were similar to those for time nursing pups with line differences being greatest during stages 1 and 2. Overall, the index was $7.0 \pm 2.2 \%$ greater $(P=0.08)$ for LS than LC dams. During stages $1-4$, dams were observed resting with pups $<1.2 \%$ of the time. Time in this activity increased drastically in stage 5 , but increased more than twice as much in LC dams than LS dams $(18.1 \%$ versus $7.65 \%, P<0.01)$, explaining the interaction of line by stage of lactation on this variable.

\section{Discussion}

The change in activity budgets over the lactation stages followed the typical pattern in mice (Priestnall, 1972, 1983; Konig and Marki, 1987; Krackow and Hoeck, 1989). The time budget for nursing behavior decreased gradually along with growth of pups during the first three stages of lactation. It increased in the fourth stage and then, in the fifth stage, decreased again (Table 5). This pattern reflects parent-offspring conflict theory. In the fourth stage, pups would be strong 


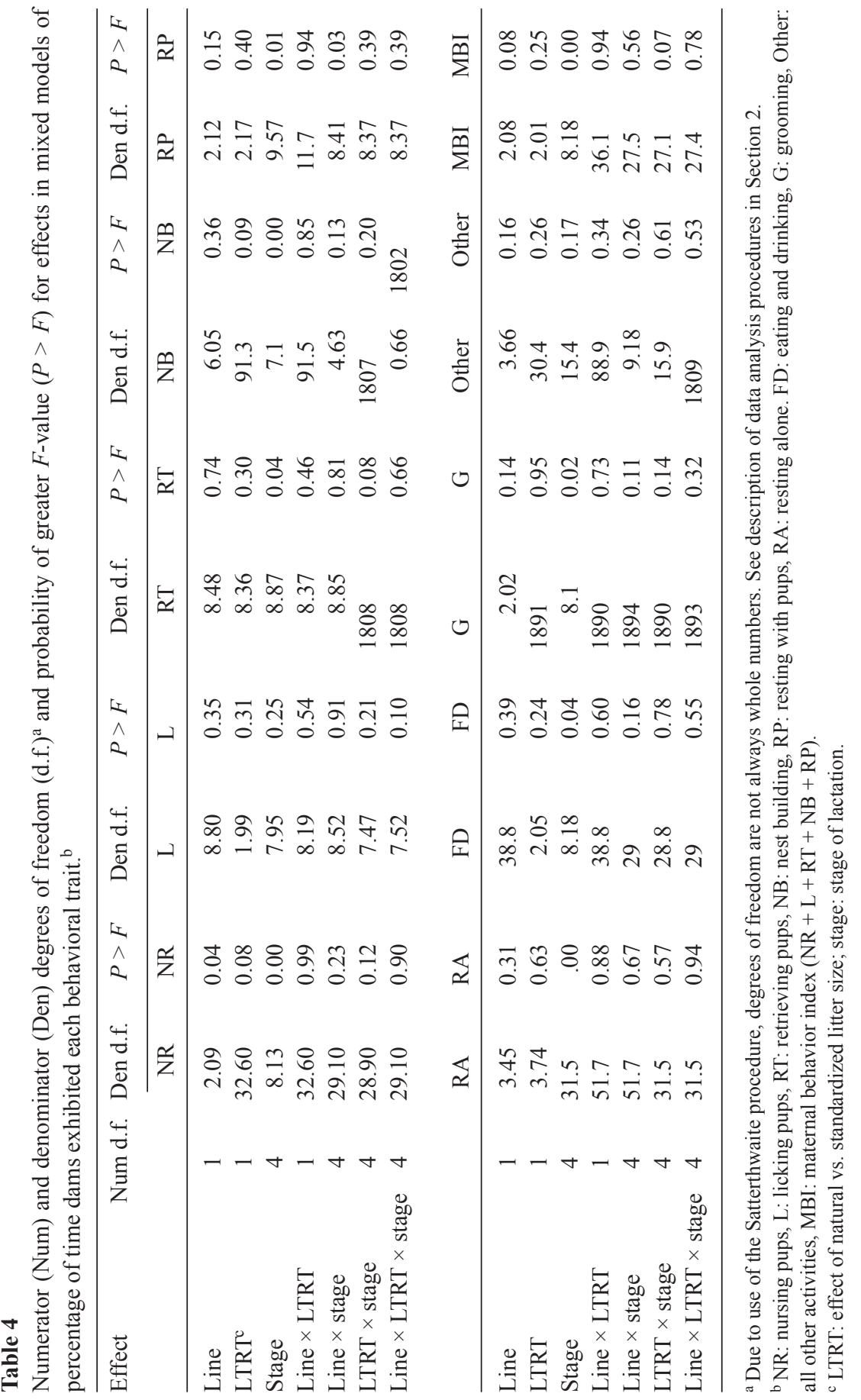


Table 5. Means and contrasts of means \pm S.E. for percentage of time litter size select (LS) and control (LC) dams were observed nursing pups (NR) and resting with pups (RP), and mean maternal behavioral index (MBI: sum of time nursing, licking, retrieving, and resting with pups, and nest building), by stage of lactations.

\begin{tabular}{|c|c|c|c|c|c|c|c|c|c|}
\hline \multirow[t]{2}{*}{ Stage ${ }^{a}$} & \multicolumn{3}{|l|}{ NR } & \multicolumn{3}{|l|}{$\mathrm{RP}$} & \multicolumn{3}{|l|}{ MBI } \\
\hline & LS & LC & $\mathrm{LS}-\mathrm{LC} \pm \mathrm{SE}$ & LS & $\mathrm{LC}$ & $\mathrm{LS}-\mathrm{LC} \pm \mathrm{SE}$ & LS & LC & $\mathrm{LS}-\mathrm{LC} \pm \mathrm{SE}$ \\
\hline 1 & 78.3 & 66.1 & $12.2 \pm 4.6^{*}$ & 0.00 & 0.04 & $-0.04 \pm 2.29$ & 85.4 & 75.5 & $9.7 \pm 4.2$ \\
\hline 2 & 70.6 & 60.8 & $9.9 \pm 4.1^{*}$ & 0.00 & 0.00 & $0.00 \pm 2.22$ & 73.4 & 62.8 & $10.5 \pm 3.7$ \\
\hline 3 & 59.7 & 54.2 & $5.5 \pm 4.1$ & 0.00 & 0.05 & $-0.05 \pm 2.23$ & 60.1 & 54.6 & $5.5 \pm 3.8$ \\
\hline 4 & 63.7 & 58.7 & $5.0 \pm 3.8$ & 0.06 & 1.14 & $-1.08 \pm 2.19$ & 63.7 & 59.3 & $3.8 \pm 3.5$ \\
\hline 5 & 51.2 & 35.3 & $15.9 \pm 3.9^{* *}$ & 7.65 & 18.10 & $-10.45 \pm 2.20 * *$ & 58.9 & 53.3 & $5.6 \pm 3.5$ \\
\hline Average & 64.7 & 55.0 & $9.7 \pm 2.1 *$ & 1.54 & 3.87 & $-2.32 \pm 1.04$ & 68.3 & 61.3 & $7.0 \pm 2.2^{+}$ \\
\hline
\end{tabular}

a Stages: $1=$ days $2-4,2=$ days $5-8,3=$ days $9-12,4=$ days $13-17$, and $5=$ days $18-22$.

${ }^{+} P<0.10 \quad * P<0.05$. ** $P<0.01$.

enough to cling to the dam even though the dam would try to avoid them. By the fifth stage, pups would be consuming more dry food and nursing less. The same pattern was also found for the maternal behavior index because nursing was a very large portion of time spent in maternal care.

Nursing behavior differed between LS and LC throughout lactation (Table 5). The ranges for time spent in nursing behavior were approximately $35-66 \%$ for LC and $51-78 \%$ for LS. Nursing behavior constituted the major component of maternal care. Averaged across stages, LS dams spent $64.7 \pm 1.4 \%$ of their time nursing pups, whereas LC dams spent $55.0 \pm 1.5 \%$ of their time nursing pups. The ranges across the five stages of time spent in total maternal care, which consisted of nest building, nursing, licking, retrieving pups and resting with pups, were $53-75 \%$ for LC and $60-85 \%$ for LS (Table 5). The time spent in maternal care activities other than nursing averaged $5.4 \%$ for LC and $3.6 \%$ for LS. On average, LS dams tended to spend more time caring for their pups than LC dams ( $68.3 \pm 2.7 \%$ versus 61.3 $\pm 2.8 \%$, respectively, $P=0.08$ ).

Priestnall (1972) standardized litters at three different sizes (2, 5, and 8$)$ to investigate the relationship between litter size and maternal care in mice and found that dams rearing smaller litters spent more time in maternal care than those with larger litters, whereas those rearing larger litters spent more time eating and drinking (litter size 8 versus 2 and 5). Extra nutrient requirement, fatigue, or discomfort for females with larger litters were postulated to be contributing to the difference. In the present study, time spent in maternal care between dams with standardized and non-standardized litters was not significant ( $67 \%$ versus $63 \%$, respectively, $P=0.25$ ) even though the average litter size dams were given an opportunity to raise was smaller in standardized than non-standardized litters, averaging 10.7 and 13.6 pups, respectively, across replications $(P=0.011)$. Behavior of individuals is due to both genetic and environmental effects. Within lines, standardizing litter size played an important role in regulating behavior; however, across lines and standardized litter size, genetic differences due to lines were greater than differences due to litter size standardization. This result agrees with Priestnall (1972) and suggests that there is a genetic difference in maternal care between LS and LC mice. 
Differences between lines were not significant for time spent licking and retrieving pups, nest building, resting alone, eating and drinking, grooming, and doing other activities. During late lactation, LC dams spent more time than LS dams resting with pups $(18.1 \pm 2.9 \%$ versus $7.7 \pm 2.9 \%$, respectively, Table 5$)$. The difference between lines during late lactation appeared to be due to different reaction of LS and LC pups to contact with their dams. On contact by dams, most pups began to suckle. Usually, LS dams tolerated suckling better than LC dams. After a period of attempting to suckle, but being rejected by their dams, LC pups appeared to learn to quit suckling, but remained in contact with dams, which was scored as resting with pups. The major function of resting with pups is assumed to be to keep pups warm, but during late lactation as pups become larger, this function would be less important. Therefore, resting with pups during late lactation might not be a necessary component of the maternal behavior index.

LS litters gained more weight during lactation than LC, especially in the standardized group (118.2 $\mathrm{g}$ versus $100.8 \mathrm{~g}, P=0.02$, Table 3 ) suggesting that LS dams have the potential to raise more pups. Quantity of milk produced was not measured, but is probably related to the difference between LS and LC for litter weight gain.

In standardized litters, LS had greater survival rate as well as greater weight gain. With natural litter size, because of some very large litters (>17 pups), with greater competition for nutrients from dams, some pups of LS dams died. In standardized litters, no LS pups died during lactation even in the second and third replicates when each dam raised 12 pups. The LC dams lost more than one pup per litter.

\section{Conclusion}

Selection for larger litters altered maternal behavior in mice. The correlated change in maternal behavior was not closely related to size of litters being nursed. Because maternal behavior changed with selection for litter size, maternal behavior is expected to respond to direct selection. Depending on levels of heritability and genetic correlations, perhaps response to direct selection for maternal behavior would be greater than correlated response observed in this study.

\section{References}

Arey, D.S., Sancha, E.S., 1996. Behaviour and productivity of sows and piglets in a family system and in farrowing crates. Appl. Anim. Behav. Sci. 50, 135-145.

Clutter, A.C., Nielsen, M.K., Johnson, R.K., 1990. Alternative methods of selection for litter size in mice. I. Characterization of base population and development of methods. J. Anim. Sci. 68, 3536-3542.

Cronin, G.M., 1985. The development and significance of abnormal tereotyped behaviours in tethered sows. Ph.D. Thesis, Agricultural University of Wageningen. 
Cronin, G.M., van Amerongen, G., 1991. The effects of modifying the farrowing environment on sow behaviour and survival and growth of piglets. Appl. Anim. Behav. Sci. 30, 287-298.

Cronin, G.M., Smith, J.A., 1992. Effects of accommodation type and straw bedding around parturition and during lactation on the behaviour of primiparous sows and survival and growth of piglets to weaning. Appl. Anim. Behav. Sci. 33, 191-208.

Cronin, G.M., Smith, J.A., Hodge, EM., Hemsworth, P.H., 1994. The behaviour of primiparous sows around farrowing in response to restraint and straw bedding. Appl. Anim. Behav. Sci. 39, 269-280.

Cronin, G.M., Simpson, G.J., Hemsworth, P.H., 1996. The effect of the gestation and farrowing environments on sows and piglet behaviour and piglet survival and growth in early lactation. Appl. Anim. Behav. Sci. 46, 175-192.

Kirby, Y.K., Nielsen, M.K., 1993. Alternative methods of selection for litter size in mice. III. Response to 21 generations of selection. J. Anim. Sci. 71, 571-578.

Konig, B., Marki, H., 1987. Maternal care in the house mouse. I. The weaning strategy as a means for parental manipulation of offspring quality. Behav. Ecol. Sociobiol. 20, 1-9.

Krackow, S., Hoeck, H.N., 1989. Sex ratio manipulation, maternal investment and behaviour during concurrent pregnancy and lactation in house mice. Anim. Behav. 37, 177-186.

Little, R.C., Milliken, G.A., Stroup, W.W., Wolfinger, R.D. 1996. SAS System for Mixed Models. SAS Inst. Inc., Gary, NC.

Lou, Z., Humik, J.R, 1994. An ellipsoid farrowing crate: its ergonomical design and effects on pig productivity. J. Anim. Sci. 72, 2610-2616.

Maderbacher, R., Schoder, G., Winter, P., Baumgartner, W., 1993. DTW Dtsch Tierarsti Wochenschr, Vol. 100, pp. 468-473.

Priestnall, R., 1972. Effects of litter size on the behaviour of lactating female mice (Mus musculus). Anim. Behav. 20, 386-394.

Priestnall, R., 1983. Postpartum changes in maternal behavior. In: Elwood, R.W. (Ed.), Parental Behavior in Rodents. Wiley, New York, pp. 67-93.

Salor, A., Salmon, M., 1971. An ethological analysis of communal nursing by the house mouse (Mus musculus). Behaviour 40, 61-85.

Schouten, W.G.P., Meunier-Salaun, M.C. 1990. Behavioral physiological changes around farrowing in Meishan, Large White and crossed-bred Dutch-Landrace? In: Molenat, M., Legault C. (Eds.), Proceedings of the Chinese Pig Symposium on Great-Yorkshire Sows. Institut National de la Recherche Agronomique, Toulouse, France, pp. 167-178.

Spicer, E.M., Driesen, S.J., Fahy, V.A., Horton, B.J., Sims, L.D., Jones, R.T., Cutler, R.S., Prime, R.W., 1986. Causes of preweaning mortality on a large intensive piggery. Aust. Vet. J. 63, $71-75$.

van der Steen, H.A.M., de Groot, P.N., 1992. Direct and maternal breed effects on growth and milk intake of pigs: Meishan versus Dutch breeds. Livestock Prod. Sci. 30, 361-374.

Vaillancourt, J.P, Tubbs, R.C., 1992. Preweaning mortality. Vet. Clin. North Am. Food Anim. Pract. 8, 685-706.

White, K.R., Anderson, D.M., Bate, L.A., 1996. Increasing piglet survival through an improved farrowing management protocol. Can. J. Anim. Sci. 76, 491-495.

Zou, S., McLaren, D.G., Hurley, W.L., 1992. Pig colostrum and milk composition: comparisons between Chinese Meishan and United State breeds. Livest. Prod. Sci. 30, 115-127. 